
made reserves, on the assumption that the replenishment of fish populations through reproduction could not happen outside them ${ }^{3}$.

Most ecologists and conservationists now accept - in theory - that even if as much as $20 \%$ of a region were cordoned off from fishing, most of that area's biodiversity would exist outside the protected zones as long as effective fisheries management was in place. Yet the dominance of MPAs in conservation policy has, if anything, increased since the 2000s.

In the past decade especially, numerous environmental NGOs and conservationfunding groups have taken up MPAs as their preferred tool for ocean protection. Together, the conservation group WWF, Greenpeace and other NGOs have spent hundreds of millions of dollars over the past ten years lobbying for MPAs around the world. One effect of this was US President Barack Obama adding just over 1 million square kilometres (an area roughly twice the size of Texas) to the US Pacific territories national monument in 2014. Another has been President James Michel of the Seychelles promising to make $412,000 \mathrm{~km}^{2}$ of the Indian Ocean surrounding the islands a totally protected MPA.

MPAs also dominate the scientific literature on marine conservation. Researchers documenting the effects of MPAs on biodiversity, in my view, ignore or underappreciate the benefits of fisheries management. Jane Lubchenco and Kirsten GrorudColvert ${ }^{4}$ for instance, have equated biodiversity protection in the oceans to the establishment of no-take areas, writing: "Even lumping all categories together, only $3.5 \%$ of the ocean is protected" and "only $1.6 \%$ is 'strongly' or 'fully' protected." And in 2014, Carissa Klein and co-authors ${ }^{5}$ evaluated the degree to which the ranges of more than 17,000 species are contained within MPAs. I interpret this as implying that species whose ranges do not fall within MPAs will be lost, although these authors concede that, for some species, "the best conservation outcome may be achieved with other strategies, including fisheries regulations".

\section{MANAGEMENT STRATEGIES}

There are many other useful tools and legal frameworks designed to reduce overfishing, rebuild fish stocks and protect the biodiversity of the oceans. National and international fisheries agencies have been developing and enforcing these for the past two decades.

Problems are identified and tools selected to solve them in what is often a highly participatory process involving many stakeholders. If a certain fishing approach, such as bottom trawling, threatens a habitat, the area can be closed to that type of fishing. If

\section{THE FRUITS OF FISHERIES MANAGEMENT}

In several areas, fish stocks are stabilizing (A, C) or increasing (B, D) thanks to catches

being limited or certain types of fishing gear being restricted in some areas.

_ Amount of fish needed to produce long-term maximum sustainable yield

\section{A Iceland and Norway}

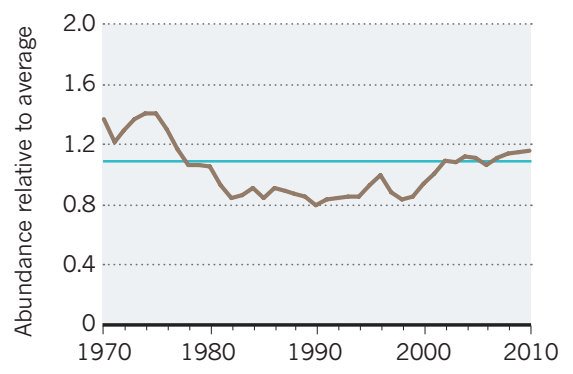

\section{US East Coast}

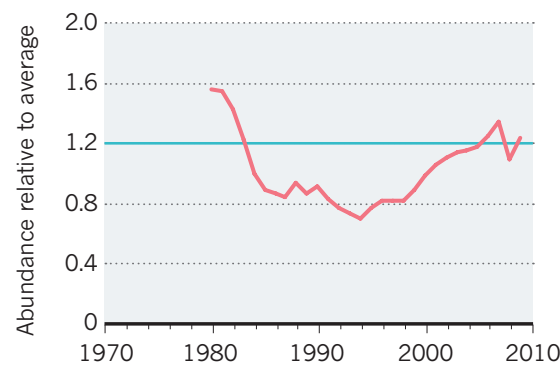

a species is being threatened as a result of being caught unintentionally along with the targeted species, the fishery may be closed, fishing permitted at only certain times of the year, or catching techniques modified to reduce by-catch. Dolphin mortality fell almost 100-fold between 1986 and 1998 in the eastern Pacific ${ }^{6}$, for instance, after vessels changed fishing practice so that ensnared dolphins were released before the nets were hauled aboard. (The technology was developed by fishermen after the Inter-American Tropical Tuna Commission instituted limits to dolphin by-catch.)

The United States spends more than US\$300 million per year on fisheries management. It does so through the implementation of key pieces of legislation, including the Magnuson-Stevens Fishery Conservation and Management Act, the Endangered Species Act, the Marine Mammal Protection Act, the National Environmental Policy Act and the Clean Water Act. In Alaska, for example, more than $50 \%$ of the continental shelf waters are closed to specific kinds of fishing gear and the entire shelf is covered by species-specific catch restrictions. This is much more protection than could be offered by turning $30 \%$ of the region into MPAs.
B EU Atlantic

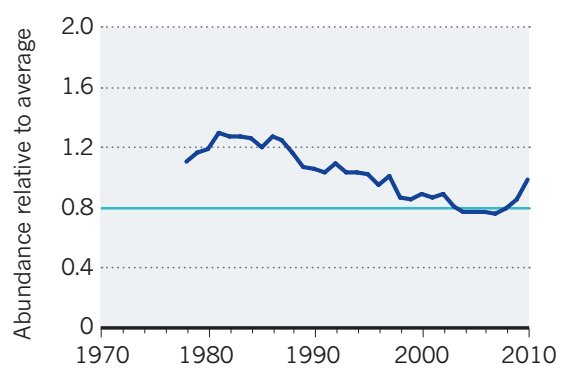

D US Southeast and Gulf of Mexico

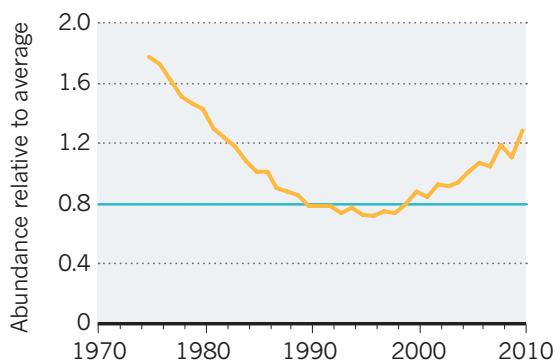

Because of fisheries management, overfishing has largely been eliminated in US waters ${ }^{7}$. The proportion of fish stocks listed as 'overfished' - those in which abundance is lower than that needed to produce near-maximum yield - halved between 1997 and 2014 to $16 \%$ (see go.nature. com/2946lg4). Overfishing has also largely stopped in the European Union's Atlantic fisheries, New Zealand, Australia, Iceland, Norway and Canada (see 'The fruits of fisheries management' $)^{8}$. And management strategies recently implemented by major Latin American countries, including Peru, Argentina and Chile, have reduced the proportion of stocks that are fished above optimal rates from $75 \%$ in 2000 to $45 \%$ in 2011 (unpublished data).

In short, it is now clear that for those countries with effective fisheries management in place - a group of nations responsible for $45 \%$ of the global catch - fish stocks are stable, or increasing. Of course, most of the world's fisheries, especially in Africa and in parts of Asia, have no protection of any kind.

\section{BRIDGE THE DIVIDE}

Studies show that enforcing the closure of an area to fishing increases the density of fish in the reserve by around $166 \%{ }^{1}$. Yet, at best, MPAs will cover a small fraction of the ocean and few studies have evaluated their effect on biodiversity outside their perimeters. Catch 


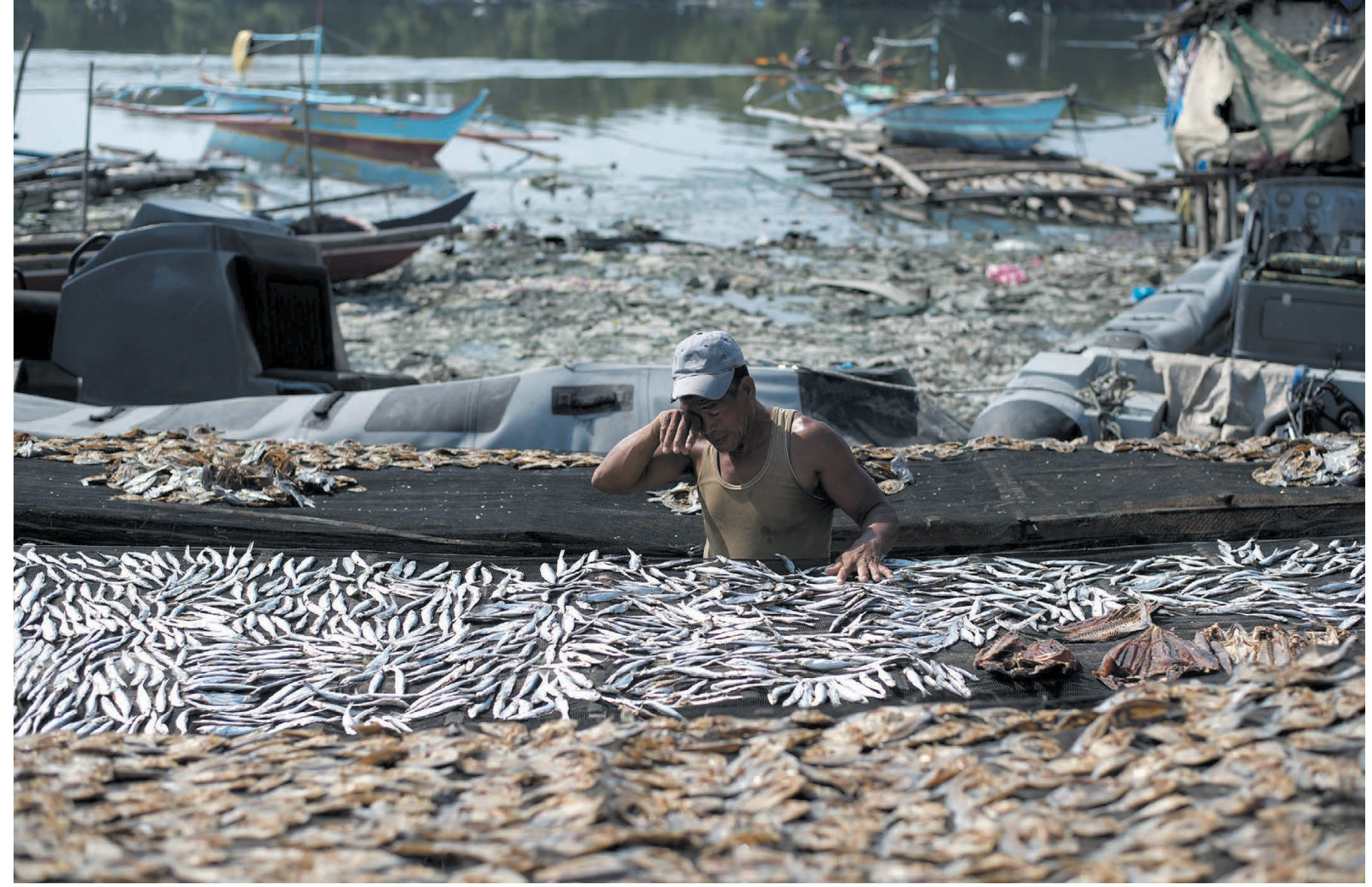

In the Philippines, communities are using a mix of protected areas and other forms of regulation to make fishing more sustainable.

data, records of boat movements and other monitoring efforts indicate that fishing pressure may increase beyond MPAs ${ }^{2}$.

More pressingly, neither MPAs nor fisheries management alone can shield marine biodiversity from the panoply of current threats: climate change and ocean acidification, land-based run-off, oil spills, plastics, ship traffic, tidal and wind farms, ocean mining and underwater communications cables.

The enormity of the challenge calls for a change in approach. Instead of working at cross purposes, MPA advocates and those in fisheries management need to identify and solve area-specific problems together, and in consultation with diverse stakeholders. These may range from professional and recreational fishermen, park officers and environmental NGOs to developers, oil and gas companies and communications companies.

Regional coastal-management agencies, such as the California Coastal Commission, which operates as a quasi-independent government agency, are a potential model. But their mandate and membership would have to be significantly expanded if they were to deal with the impacts of fisheries and the establishment of MPAs. Such commissions have traditionally been confined to nearshore waters and have been able to regulate only development permits.

Marine spatial planning is a generic term for the process of resolving conflicts in the use of marine resources and would seem to be the obvious mechanism to integrate fisheries management and MPAs. Yet after more than a decade of discussion and some attempts at implementation, there are few examples of the process effectively bringing the two 'tribes' together to work towards common goals. I suspect that this is, in part, because insufficient efforts have been made to convince both parties that decisionmaking bodies represent their interests appropriately.

The best examples of MPA advocates and fisheries-management communities working together are small-scale. In the Philippines and Indonesia, for instance, communities are working with local governments and NGOs, using a mix of protected areas and other forms of regulation, to try to rebuild coral-reef fish stocks ${ }^{9}$. Here the principal aim is to make fishing more sustainable; the objective of protecting representative habitats is not typically considered.

In larger industrial fisheries, such as in Europe, Australia and New Zealand, it should be possible for MPA advocates to collaborate with national fisheries departments. This would require a clear elaboration of the objectives of each. It would also require the appointment of more conservationists and MPA advocates to fisheries-management organizations, which are currently dominated by regulatory agencies and fishinginterest groups.

Another way to foster collaboration on a national scale would be to merge the various government departments responsible for conservation and fisheries management into a single department of marine management.
Such an organization could oversee the protection of biodiversity and the sustainable use of fisheries, and regulate competing marine uses. As a first step, a set of formal consultations, informed by case studies that measure the actual level of biodiversity protection achieved in different places through existing mixes of MPAs and fisheries management, could begin to identify clear measurable objectives.

At the local, national and international levels, biodiversity protection and fisheries management must be overseen by the same bodies if either is to be truly effective.

Ray Hilborn is professor in the School of Aquatic and Fisheries Sciences at the University of Washington, Seattle, USA. e-mail:rayh@uw.edu

1. Lester, S. E. et al. Mar. Ecol. Progr. Ser. 384, 33-46 (2009).

2. Hilborn, R. et al. Ocean Coast. Mgmt 47, 197-205 (2004).

3. Lubchenco, J., Gaines, S. D., Warner, R. R., Airame, S. \& Simler, B. The Science of Marine Reserves (Partnership for Interdisciplinary Studies of Coastal Oceans, 2002); available at http://www.piscoweb.org

4. Lubchenco, J. \& Grorud-Colvert, K. Science 350, 382-383 (2015).

5. Klein C. J. et al. Sci. Rep. 5, 17539 (2015).

6. Hall, M. A., Alverson, D. L. \& Metuzals, K. I. Mar. Pollut. Bull. 41, 204-219 (2000)

7. Ocean Studies Board. Evaluating the Effectiveness of Fish Stock Rebuilding Plans in the United States (National Academies Press, 2014).

8. Costello, C. et al. Science 338, 517-520 (2012).

9. Christie, P., Campbell, L. \& Armada, N. in Governance of Marine Fisheries and Biodiversity Conservation (eds Garcia, S. M., Rice, J. \& Charles, A.) 332-345 (Wiley-Blackwell, 2014). 